\title{
Two fatal cases of septicaemia due to Erysipelothrix insidiosa
}

\author{
CHRISTOPHER A. MORRIS, HERTA SCHWABACHER, PATRICK G. LYNCH, \\ CLARA D. CROSS, AND TITUSO. DADA
}

From Group 9 Laboratory, Watford, and St. Martin's Hospital, Bath

SYNOPSIS Clinical, pathological, and necropsy findings are recorded from two cases of endocarditis due to Erysipelothrix insidiosa, one in a 53-year-old grocer and the other in a 56-year-old housewife. The possible sources of infection are suggested.

Langford and Hansen (1954) have suggested that the genus Erysipelothrix possesses a single species Erysipelothrix insidiosa and that subdivision into further species is not justified; following their terminology $E$. insidiosa and $E$. rhusiopathiae in this account are considered synonymous.

Erysipelothrix rhusiopathiae is recognized as the pathogen causing the skin lesions of human erysipeloid. This condition most often occurs as an occupational hazard of meat and fish handlers, veterinarians, laboratory staff, and others exposed to meat and fish products in industry and the home. The organisms occur in nature in putrefying and decaying matter and are commensals of the oropharynx of domestic animals, in fish slime and scales, in birds, rodents, and in more exotic creatures, including the kangaroo, wild bear, and mink (Woodbine, 1950).

When pathogenic, the portal of entry is usually through a skin abrasion, though Fiessinger and Brouet (1934) have recorded septicaemia due to $E$. insidiosa following ingestion of infected salt pork, and Rowsell (1955) has demonstrated by experiments on swine that the oral route may play a role. In pigs infection is common either as a minor cutaneous form (swine erysipelas), or as an acute and often fatal septicaemia of chronic arthritis or endocarditis. Human infection is uncommon and almost always limited to the cutaneous form.

Published accounts of endocarditis due to $E$. insidiosa are few and none appear to our knowledge in the British literature. Two recent isolations made from fatal cases of subacute bacterial endocarditis, diagnosed before death and confirmed at necropsy, are discussed in this record.

Received for publication 1 April 1965.

\section{CASE REPORTS}

CASE 1 K.T., a 53-year-old grocer, gave a history of uninvestigated limb pains and swollen knees when aged 30. For two years he occasionally had had muscle $\bullet$ cramps of the abdomen and calves precipitated by cold $\mathrm{G}$ weather. For one month before admission he had a dry unproductive cough, lassitude, night sweats, and generalized muscular aches and pains. He was admitted to Shrodells Hospital on 10 January 1964 under the care of Sir John Richardson. On examination he was noted to be

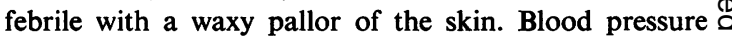
was $120 / 70 \mathrm{~mm}$. $\mathrm{Hg}$, and the pulse rate 108 per minute $\overrightarrow{\vec{\sigma}}$ and of regular rhythm. Loud generalized diastolic and 3 systolic murmurs were heard over the praecordium. The spleen was palpable. No other abnormal physical signs were recorded. A clinical diagnosis of bacterial endocarditis was made.

Investigations showed haemoglobin $8.5 \mathrm{~g} . / 100 \mathrm{ml}$. (14.6 g./100 ml. as $100 \%$ ); total white blood cells $4,000 \exists$ per c.mm. $(82 \%$ neutrophils, $13 \%$ lymphocytes, $5 \%$ monocytes); E.S.R. $68 \mathrm{~mm}$. Westergren (first hour); 욱 platelets 80,000 per c.mm. A specimen of midstream urine showed no sugar or albumin, an occasional $\frac{\text { 의 }}{3}$ deposit of leucocytes, but no red cells. Five blood cultures $>$ yielded a Gram-positive bacillus. Treatment was started on 15 January with 1 mega unit penicillin six hourly and $\bar{N}$ the temperature settled immediately. On 18 January a splinter haemorrhage was noted beneath the nail of the $N$ right middle finger. Three days later the patient developed $N$ ankle oedema and marked dyspnoea. The jugular venous $\omega$ pressure was raised and there were crepitations over the bases of both lungs. His condition gradually deterioratedo and he died on 26 January 1964.

Post-mortem findings Necropsy was performed by $\stackrel{\mathscr{N}}{?}$ Dr. P. G. Lynch.

The cadaver was that of a male subject. Dorsalo lividity was present. There was a splinter haemorrhage $\mathbb{\Phi}$

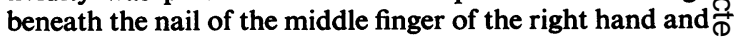
minimal finger clubbing. A few small petechial haemor- 
rhages were present on the skin over the dorsum of the chest.

The pericardium and endocardium were normal. The pericardial sac contained a moderate quantity of clear, straw-coloured fluid. The myocardium was of flabby consistency. The left ventricle was dilated and $10 \mathrm{~mm}$. thick. The mitral valve appeared healthy (circumference $10 \mathrm{~cm}$.). There were numerous small vegetations on the inferior surface of the aortic valve cusps and the right coronary cusp of the aortic valve was perforated, together with severe erosion of the left coronary cusp. The aortic valve ring measured $8 \mathrm{~cm}$. The right ventricle was $4 \mathrm{~mm}$. thick. The tricuspid and pulmonary valves appeared healthy (circumference $13 \mathrm{~cm}$. and $9 \mathrm{~cm}$. respectively). The heart weighed $420 \mathrm{~g}$.

The nares, larynx, trachea, and main bronchi were normal. Both lungs were intensely congested and oedematous, the right lung weighing $1,040 \mathrm{~g}$. and the left $640 \mathrm{~g}$. Both pleural cavities contained large quantities of clear, straw-coloured fluid.

The mouth, tongue, pharynx, oesophagus, stomach, and intestines appeared normal. The liver was congested and weighed $2,295 \mathrm{~g}$. There were no abnormalities of the biliary apparatus or pancreas.

The spleen was enlarged ( $426 \mathrm{~g}$.) and had a large pale yellow infarct in its substance. There were no naked-eye abnormalities of the thyroid, pituitary, and suprarenals. Unfortunately a bone marrow biopsy was not performed.

The subcapsular surfaces of both kidneys were smooth and slightly lobulated; the cut surfaces of both organs showed no naked-eye abnormalities. The right kidney weighed $207 \mathrm{~g}$. and the left $216 \mathrm{~g}$. The ureters, bladder, prostate gland, and testes were normal.

There were no naked-eye abnormalities of the skull and meninges. A few minute petechial haemorrhages were visible in the white matter of the frontal lobe of the right cerebral hemisphere. The brain weighed $1,540 \mathrm{~g}$. There were flecks of atheroma in the vessels of the circle of Willis. The venous sinuses showed no abnormality.

CASE 2 Mrs. T., a 56-year-old housewife, gave a history of increasing lassitude for one year and loss of a stone in weight over six months. Two months before admission she was treated symptomatically for a febrile upper respiratory infection with non-productive cough and backache and showed some improvement until four weeks later when she again became febrile and was found to be in congestive cardiac failure with leg oedema. Clinically her urine appeared infected. For domestic reasons she declined further investigations or hospital admission and so was treated with tetracycline, digoxin, and diuretics. Following temporary improvement, she developed 'cafe au lait' skin pigmentation and one week before admission her condition again deteriorated and she consented to enter hospital. She was admitted on 22 March 1964 to St. Martin's Hospital under the care of Dr. J. A. Cosh. On examination she was an asthenic afebrile woman with 'cafe au lait' skin pigmentation and gross finger clubbing. There were no splinter haemorrhages, Osler's nodes, or ankle or sacral oedema. The blood pressure was $120 / 90 \mathrm{~mm}$. $\mathrm{Hg}$ and pulse rate 100 per minute and regular in rhythm. The jugular venous pressure was raised $3 \mathrm{~cm}$. The apex beat was in the fifth interspace just outside the left mid-clavicular line and the impulse was left ventricular in type. There were no thrills. In the mitral area there was a pansystolic murmur conducted to the axilla, and a short diastolic murmur. The pulmonary second heart sound was accentuated. The spleen and liver were not palpable and there was no other evidence of embolic disease. She was admitted on a clinical diagnosis of bacterial endocarditis.

Investigations showed haemoglobin $7.5 \mathrm{~g} . / 100 \mathrm{ml}$. (14.6 g. $/ 100 \mathrm{ml}$. as $100 \%$ ); P.C.V. $28 \%$; M.C.H.C. $26 \%$; total white blood cells 10,000 per c.mm. $(92 \%$ neutrophils, $8 \%$ lymphocytes, $0 \%$ monocytes); E.S.R. $76 \mathrm{~mm}$. Westergren (first hour); platelets 185,000 per c.mm. A specimen of midstream urine showed no sugar, protein $100 \mathrm{mg}$. per $100 \mathrm{ml}$, and a deposit of numerous red blood cells, moderate numbers of white blood cells, and scanty granular casts. Several blood cultures, taken during the first few days of admission were, sterile. Five days after admission she developed a right hemiplegia accompanied by acute pyrexia. Blood cultures taken at this stage and the following day yielded Gram-positive bacilli. After intensive therapy with intramuscular crystalline penicillin, 4 megaunits followed by 2 megaunits four-hourly together with Probenicid $0.5 \mathrm{~g}$. twice daily, her general condition improved and her temperature returned to normal. Two days before her death she gradually lapsed into coma and died $\mathbf{1 7}$ days after admission to hospital.

Post-mortem findings The cadaver was that of a tall thin female. There was marked finger clubbing. No splinter haemorrhages or petechiae were found.

The two pericardial layers were lightly adherent over the whole surface. The heart was enlarged, chiefly on the right side with dilatation and hypertrophy of both chambers. It weighed $400 \mathrm{~g}$. Very severe bacterial endocarditis was affecting the mitral, aortic, and tricuspid valves, the vegetations being largest on the mitral valve where they were present in clusters each 2 to $3 \mathrm{~mm}$. across. Severe ulceration had spread beyond the valve on to the inner surface of the left auricle; the left auricle and left ventricle and the valve cusps were largely destroyed. The aortic and tricuspid valves were similarly affected, the left posterior cusp of the aortic valve being perforated. The pulmonary valve alone appeared healthy. No evidence of pre-existing carditis was found, either macroscopically or microscopically. The arteries showed minimal sclerosis.

The pharynx and larynx were normal. The trachea and bronchi were filled with semi-purulent exudate. The lungs showed moderate generalized emphysema. The pleurae were normal.

The mouth, tongue, pharynx, oesophagus, stomach, and intestines appeared normal. The liver showed advanced chronic venous congestion. There were no abnormalities of the biliary apparatus and pancreas.

The spleen was swollen and congested, with one old infarct $3 \mathrm{~cm}$. in diameter at the peritoneal surface, shrunken well below the surface. There were no nakedeye abnormalities of the thyroid, pituitary, or suprarenals.

The left kidney was normal. The right kidney showed 
a dense, white, old infarct involving the whole upper pole. The ureters and bladder were normal as were the uterus and its appendages.

No naked-eye abnormalities of the skull and meninges were found. There was a recent infarct involving much of the anterior part of the left temporal lobe. The cerebral arteries showed minimal sclerosis. The venous sinuses showed no abnormalities.

\section{BACTERIOLOGY}

The strains were isolated by blood culture in liquoid or glucose broths. They were facultative anaerobes growing on simple media. On primary isolation the short, slender and sometimes curved bacilli were Gram-variable; subcultures were constantly Gram-positive and tended to form filaments.

Sneath, Abbott, and Cunliffe (1951) have given a detailed account of the bacteriology' of a number of strains of E. insidiosa. Morphologically, culturally, and biochemically neither of the two isolations under discussion can be considered unique; in most respects both resembled Erysipelothrix rhusiopathiae, N.C.T.C. 8163, with which they were compared. All three strains showed characteristic differences from the morphologically similar but taxonomically different Listeria monocytogenes Type 1, N.C.T.C. 7973, particularly in the production of alpha haemolysis on horse blood agar, the absence of a soluble haemolysin, sensitivity to potassium tellurite, lack of mobility at $22^{\circ} \mathrm{C}$. and $37^{\circ} \mathrm{C}$., the absence of catalase, restricted fermentation spectrum and weak formazan production from 2-3-5 tripheny tetrazolium chloride (T.T.C.). Both the current isolates differed from N.C.T.C. 8163 in their tolerance to bile salts; they grew in $5 \%$ sodium taurocholate broth and on MacConkey's bile salt agar and in this resembled Listeria. The characteristic gelatin stab 'lamp brush' appearances were only present after several weeks' incubation.

Both the current strains were sensitive by disc test to penicillin, methicillin, tetracycline, erythromycin, chloramphenicol, ampicillin, and fucidin but were resistant to sulphonamides and neomycin. The minimum inhibiting concentration of penicillin by the agar plate dilution and glucose serum broth methods was 0.06 units per $\mathrm{ml}$.

Virulence tests were performed on mice and rabbits. In mice the intraperitoneal inoculation of $0.1 \mathrm{ml}$. of an overnight broth culture containing $250 \times 10^{7}$ viable organisms calculated by the technique of Miles and Misra (1938) was lethal in 48 to 72 hours, death being preceded by severe conjunctivitis. Heart blood smears and cultures from the cadavers were positive. In rabbits an intravenous sublethal dose of 6 to $8 \times 10^{5}$ viable organisms promoted a monocyte response in the peripheral blood from a basal 1 to $4 \%$, rising on the fourth to the eighth day to from 10 to $22 \%$. This type of response has been recorded by Wilson and Miles (1964) reaching itso maximum in three to seven days.

\section{SEROLOGICAL NOTES ON CASE 1}

This patient's serum showed an agglutinating titre of $1: 128$ against the infecting strain, and electro-.

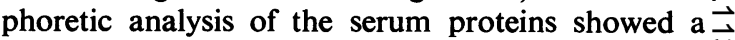
sharply defined band in the gamma globulin zone. $\omega$ Immunodiffusion tests against antihuman serum $\overline{ }$ showed that this band was not gamma globulin and? that the patient was deficient in gamma globulin. The $\vec{\infty}$ serum from a rabbit immunized with the infecting 0 strain produced no similar electrophoretic band. It seems probable that the abnormal protein was present 0 in the patient's serum before the septicaemia and was not a response to infection. The protein remains $c s$ incompletely identified.

\section{OBSERVATIONS ON THE LITERATURE}

Rosenbach (1884) first described human erysipeloid $\vec{\bullet}$ and claims to have isolated the organism from an of infected finger (1909). The bacillus was originally described in mouse blood by Koch (1880) and was found by Loeffler (1886) in the blood of pigs dying of swine erysipelas.

In 1912 Günther reported two fatal cases of $\frac{0}{D}$

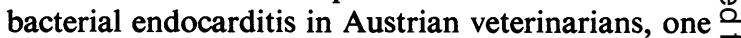
following self inoculation with swine vaccine, and in $\overline{\overrightarrow{0}}$ 1921 Prausnitz described an 'erysipeloid bacillus' isolated six times from the blood of a 10-year-old girl with a congenital heart lesion; permission for subsequent necropsy was refused.

The first antemortem and post-mortem bacteriologically proven case was that of Russell and Lamb 3 . (1940), a lobster fisherman with preceding rheumatic carditis. Klauder, Kramer, and Nicholas (1943) obtained blood culture and histological evidence 0 from a butcher with endocarditis and an erysipeloid lesion of a lacerated thumb. The medical student $\frac{7}{0}$ described by Jimenez Casado, Ales, and Ortiz Masllorens (1960) may have acquired his fatal of infection from a bacteriological laboratory. Necropsy $N$ was not allowed. Harvier, Turiaf, and Crosnier N (1954) compared the post-mortem findings in a 50-year-old tanner with those previously recorded in swine, and these same authors recall Kissell's $\stackrel{\varrho}{=}$ 33-year-old patient with past rheumatic carditis $\stackrel{\infty}{\varnothing}$ whose terminal erysipelothrix endocarditis is recorded in Plissier's thesis of 1950.

Lawes, Durie, Goldworthy, and Spies (1952) gave $\stackrel{\vec{D}}{\mathbb{D}}$ the first report of a successfully treated case of $\frac{?}{\mathbb{D}}$ erysipelothrix endocarditis. A butcher recovered 
after systemic penicillin as did a second butcher similarly treated and recorded by McCarty and Bornstein (1960). Schiffman and Black (1956) give an account of successful antibiotic therapy on a construction worker who developed acute endocarditis following contamination of a grazed finger with 'land fill' from a pig farm. Theodorescu, Seropian, and Greceanu (1960), and Seropian, Greceanu, and Theodorescu (1961) treated a housewife who developed local erysipeloid followed by endocarditis after eating undercooked infected pork; the patient recovered. In all these successfully treated cases, $E$. insidiosa had been recovered from multiple blood cultures.

\section{DISCUSSION}

The source of infection of both patients is speculative; it is however pertinent to record that the wife of K.T. volunteered the information that her husband had often cut himself when carving pork products, and Mrs. T. frequently scaled fresh fish for her cat.

A possible predisposing factor in K.T. is the evidence of hypogammaglobulinaemia, the latter inhibiting a normal antibody response. Although there is no relevant past history for Mrs. T., her episode of heart failure following a year of increasing lassitude, together with the presence of marked finger clubbing, may reflect preceding cardiopathy. In neither patient at necropsy was evidence found of a congenital heart lesion nor of histological stigmata of rheumatic carditis.

On admission to hospital both patients showed relatively low leucocyte counts consistent with the septicaemic phase. K.T. was pyrexial and early blood cultures confirmed the clinical diagnosis. Bacteriological confirmation in the case of Mrs. T. was hampered by antibiotic cover at the time of her entry to hospital.

In spite of intensive antibiotic therapy both patients died and extensive endocardial damage and evidence of embolic episodes were noted at necropsy. It is evident that in a susceptible subject this infection is highly virulent and early diagnosis essential to avoid an irreversible state. E. insidiosa is very sensitive to penicillin by tests in vitro; that this is true in vivo is supported by the reports in the literature of successful treatment, and in the present cases in the inability to recover the organisms from the heart vegetations of K.T.; positive cultures were obtained from the heart valves of Mrs. T. but probably represented scanty survivors protected within the gross vegetation which could not be demonstrated by a careful histological search.

The three Erysipelothrix strains tested (K.T., Mrs. T., N.C.T.C. 8163) showed neomycin resistance and weak formazan production unlike Listeria monocytogenes type 1 N.C.T.C. 7973. Füzi (1963) has suggested neomycin resistance as a useful adjunct to that of penicillin sensitivity in the differentiation of Erysipelothrix and Listeria. The different rates of formazan production (Dias and da Silva, 1958) between these two genera in two hours would appear to reflect primarily their different metabolic rates.

We wish to thank Sir John Richardson and Dr. John Cosh for permission to report the case histories of K.T. and Mrs. T. respectively, Miss Hilda Taylor, F.I.M.L.T., of Watford, and Mr. G. D. Curtis, F.I.M.L.T., of Bath, who made the primary isolations. We are indebted to the late Dr. K. J. Steel of the National Collection of Type Cultures who provided the bacterial strains for comparative study and also confirmed the identity of both current strains.

\section{REFERENCES}

Dias, V. M., and Silva, N. P. M. da (1958). Mem. Inst. Osw. Cruz, 56, 477.

Fiessinger, N., and Brouet, G. (1934). Presse méd., 42, 889.

Füzi, M. (1963). J. Path. Bact., 85, 524.

Günther, G. (1912). Wien. klin. Wschr., 25, 1318.

Harvier, P., Turiaf, J., and Crosnier, J. (1954). Sem. Hôp. Paris, 30, 555.

Jimenez Casado, M., Ales, J. M., and Ortiz Masllorens, F. (1960). Rev. clin. esp., 77, 411.

Klauder, J. V., Kramer, D. W., and Nicholas, L. (1943). J. Amer. med. Ass., 122, 938.

Koch, R. (1880). Investigations into the Etiology of Traumatic Infective Diseases. New Sydenham Society, London.

Langford, G. C., and Hansen, P. A. (1954). Antonie v. Leeuwenhoek, 20, 87.

Lawes, F. A. E., Durie, E. B., Goldworthy, N. E., and Spies, H. C. (1952). Med. J. Aust., 1, 330.

Loeffler, F. A. I. (1886). Arb. Gesundh. -Amte (Berl.) 1, 46

McCarty, D., and Bornstein, S. (1960). Amer. J. clin. Path., 33, 39.

Miles, A. A., and Misra, S. S. (1938). J. Hyg. (Lond.), 38, 732.

Plissier, M. (1950). Thèse Méd., Paris.

Prausnitz, C. (1921). Zbl. Bakt., I. Abt. Orig., 85, 362.

Rosenbach, F. J. (1884). Micro-organismen bei den Wund-infectionskrankheiten des Menschen, p. 117. Bergmann, Wiesbaden.

(1909). Z. Hyg. Infekt.-Kr., 63, 343.

Rowsell, H. C. (1955). Proc. Amer. vet. med. Ass., 92, 143.

Russell, W. O., and Lamb, M. E. (1940). J. Amer. med. Ass., 114, 1045

Schiffman, W. L., and Black, A. (1956). New Engl. J. Med., 255, 1148.

Seropian, E., Greceanu, I., and Theodorescu, B. (1961). Med. interna (Buc.), 13, 1183.

Sneath, P. H. A., Abbott, J. D., and Cunliffe, A. C. (1951). Brit. med. J., $2,1063$.

Theodorescu, B., Seropian, E., and Greceanu, I. (1960). Bull. Soc. méd. Hôp. Paris, 76, 1125.

Wilson, G. S., and Miles, A. A. (1964). In Topley and Wilson's Principles of Bacteriology and Immunity, 5th ed., vol. 1, p. 529. Arnold, London.

Woodbine, M. (1950). Bact. Rev., 14, 161. 